\title{
A Giant Superior Mesenteric Artery Aneurysm Mimicking an Abdominal Aortic Aneurysm
}

\author{
Wouter Hogendoorn, Felix J.V. Schlösser, Bauer E. Sumpio* \\ Section of Vascular Surgery, Department of Surgery, Yale University School of Medicine, New Haven, Connecticut
}

\begin{abstract}
Superior mesenteric artery aneurysms are a rare clinical finding but can present with a wide range of symptoms. They are associated with a high risk of rupture, as well as high morbidity and mortality. We present a case of a 38-year-old female who presented with acute abdominal pain and a pulsatile palpable mass in the right epigastric region without other signs or symptoms. Copyright $\odot 2013$ Science International Corp.
\end{abstract}

\section{Key Words}

Aneurysm - Superior mesenteric artery

\section{Introduction}

Visceral artery aneurysms (VAAs) are a rare entity in clinical practice, with a reported incidence ranging from $0.1 \%$ to $2 \%$. Splenic artery and hepatic artery aneurysms account for the majority of these aneurysms (60\% and $20 \%$, respectively). Although only $5.5 \%$ of VAAs are attributable to superior mesenteric artery aneurysms (SMAAs) [1,2], they are clinically important because of the high risk of rupture and death (up to 40\%) [2,3]. Two decades ago, most patients with SMAAs presented with fever, abdominal pain, and a pulsatile abdominal mass and had an infection as an underlying cause [4,5]. Because of the increased use of computed tomography (CT) scans and other cross-sectional imaging, the incidence of detected SMAAs is rising, and more SMAAs are asymptomatic. We report on a patient who presented with a large

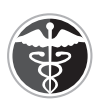

Fax +1 2037853346

E-Mail: aorta@scienceinternational.org

http://aorta.scienceinternational.org

\section{(c) 2013 Aorta.}

Published by Science International Corp. ISSN 2325-4637

\section{Accessible online at:}

http://aorta.scienceinternational.org pulsatile mass mimicking an abdominal aortic aneurysm (AAA). A giant SMAA was found and subsequently treated successfully.

\section{Case Report}

A 38-year-old white female presented to the emergency department with abdominal pain that started 48 hours before admission and was not associated with nausea or vomiting. On examination, she was afebrile, and a pulsatile mass in the right epigastric region was appreciated (Fig. 1). The vascular surgery service was emergently consulted to manage a symptomatic AAA. A CT scan of the abdomen was obtained that revealed a $6 \times 7-\mathrm{cm}$ SMAA (Fig. 2), which was confirmed by angiography (Fig. 3). Emergent transperitoneal laparotomy was performed, and a giant aneurysm, $\approx 8 \mathrm{~cm}$ distal from the origin of the superior mesenteric artery (SMA), was excised successfully; continuity was restored with a reversed saphenous vein graft (Fig. 4). The patient had an uneventful recovery and was doing well at 5-year follow-up. Pathological examination of the surgical specimen revealed degenerative changes in the arterial wall and large amounts of thrombus. No bacteria were identified microscopically. Culture of the aneurysm wall did not grow any bacteria.

${ }^{*}$ Corresponding author:

Bauer E. Sumpio

Yale University School of Medicine

Section of Vascular Surgery

333 Cedar Street, BB 204

New Haven, CT 06510 (USA)

Tel. +1 203785 6217, Fax +1 203785 7609, E-Mail: bauer.sumpio@yale.edu 


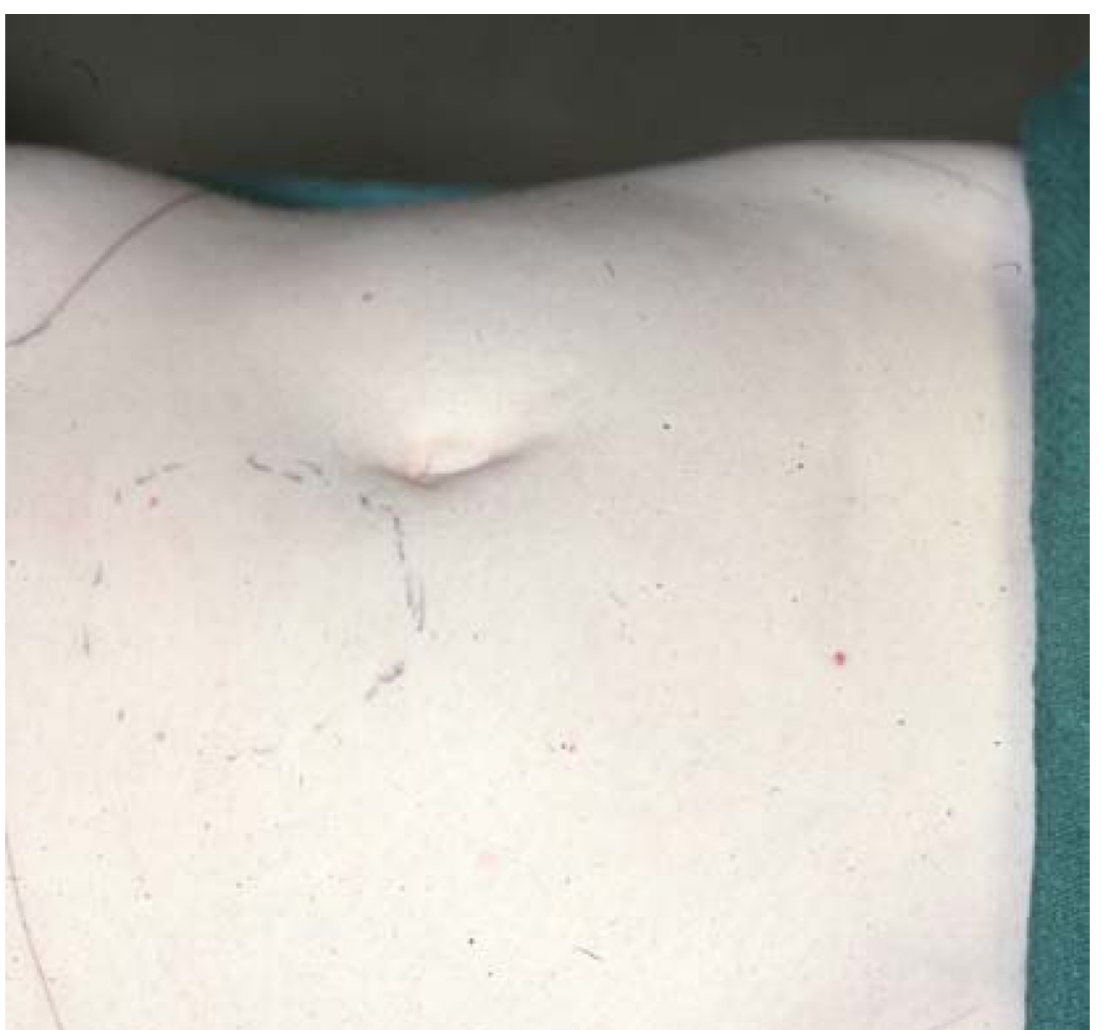

Figure 1. Marking indicates the location of the pulsatile mass in the right epigastric region.

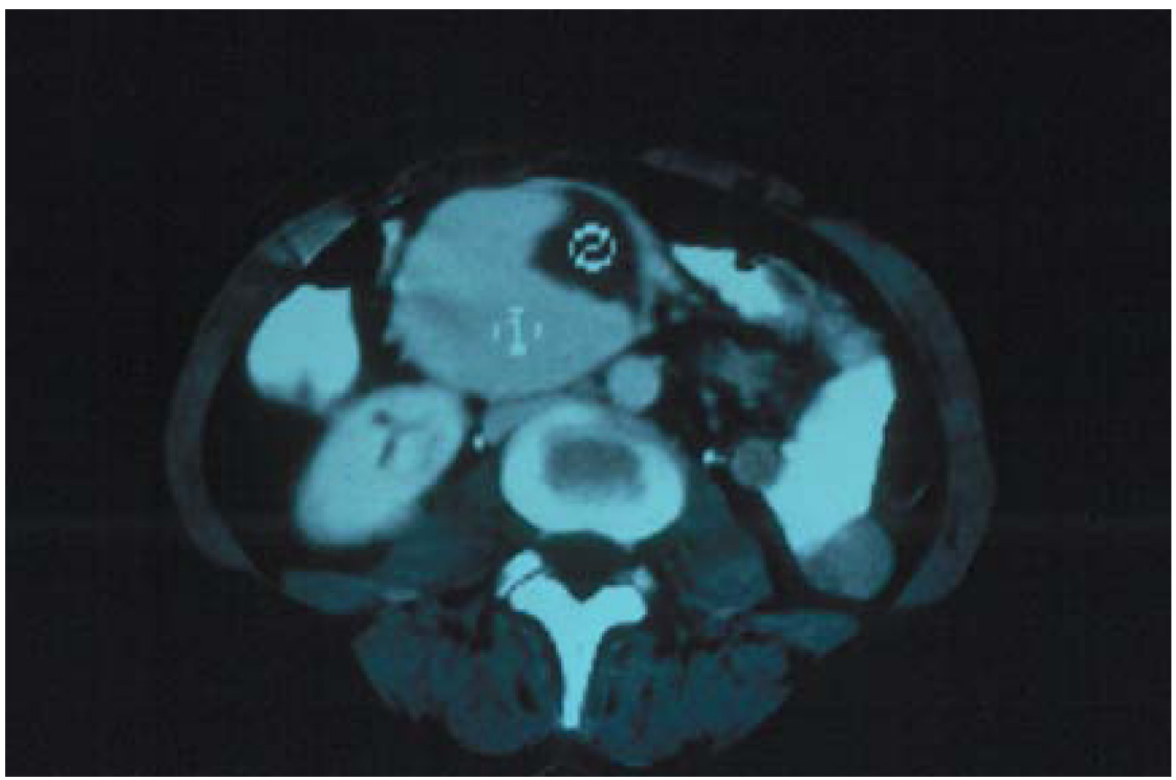

Figure 2. Computed tomography of the abdomen showing a large saccular aneurysm of the superior mesenteric artery, $6 \times 7$ $\mathrm{cm}$ in width and diameter. 


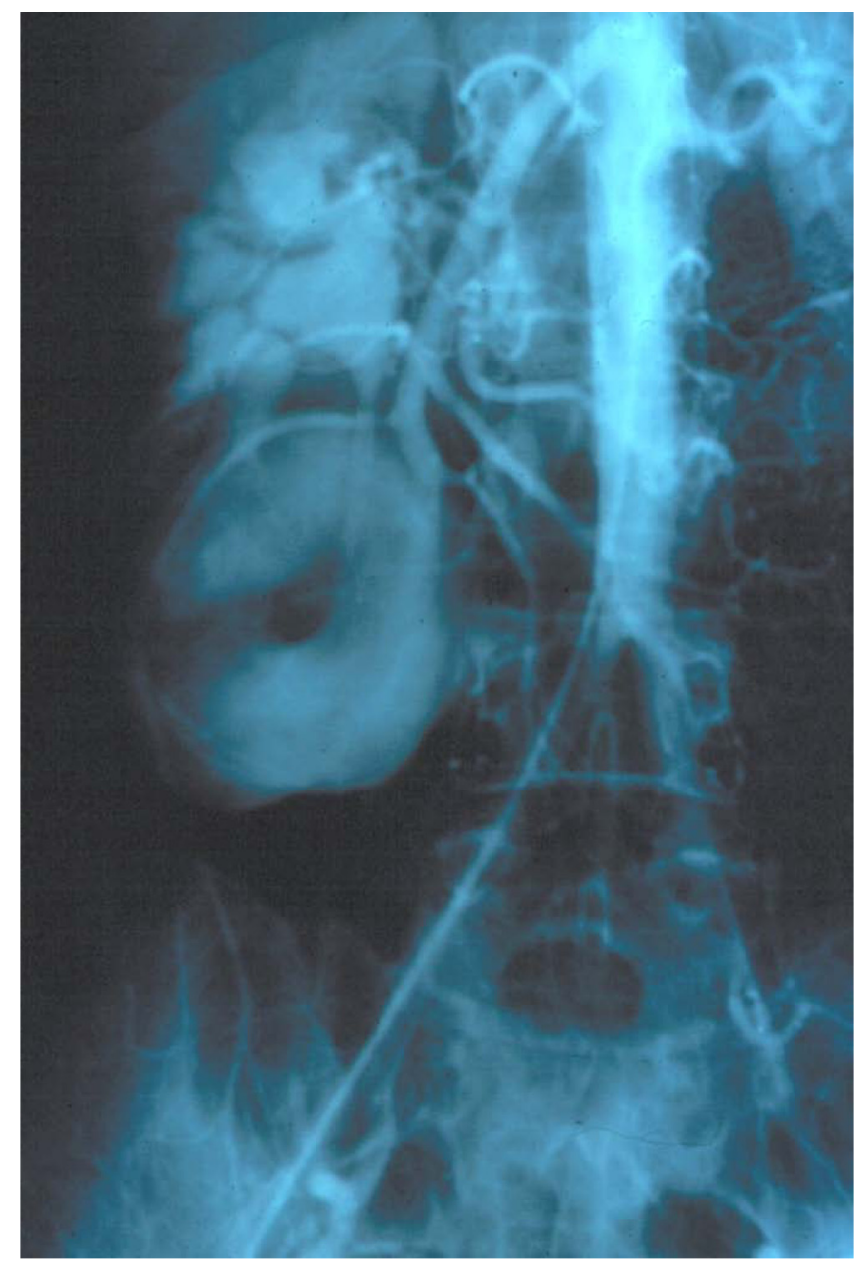

Figure 3. Abdominal angiography showing a superior mesenteric artery (SMA) aneurysm, $8 \mathrm{~cm}$ from the origin of the SMA and with a length of $7 \mathrm{~cm}$.

\section{Discussion}

Aneurysms of the SMA are rare and account for $5.5 \%$ of all VAAs. Because of this very low incidence, large studies documenting their outcomes are lacking in literature. DeBakey and Cooley [6] described the first successful resection without revascularization of a mycotic SMAA caused by bacterial endocarditis in a young female in 1953. Studies with $>5$ patients with SMAAs are shown in Table 1 [2,7-9]. SMAAs are usually located within the first $5 \mathrm{~cm}$ from the origin of the SMA and can be fusiform or saccular [10]. In contrast to most other aneurysms, both men and women are equally affected, although men are reported to have a higher rupture risk [2]. There is no typical age of onset of SMAAs, which depends primarily on the cause of the disease. Most patients with mycotic aneurysms are younger than 50 years of age, and patients with atherosclerotic aneurysms are usually in their seventh or eighth decade [11]. The fact that it is a disease that can affect patients of all ages is illustrated by the case of a 9-year-old boy with Ehlers-Danlos syndrome and an SMAA [12].

Historically, mycotic aneurysms have represented the majority of all SMAAs, with a reported percentage up to 63\% [13], and most were caused by nonhemolytic Streptococci, although a wide range of other pathogens have been reported. Currently, the most frequent cause of aneurysms of the SMA is atherosclerosis. This is underscored by a series from the Mayo Clinic in which only $5 \%$ of patients were thought to have infection as the primary cause for the aneurysm, whereas $62 \%$ of the patients had calcified SMAAs [2]. Other more recent reports validate this finding [8]. Despite the relatively small number of reports, a wide range of other causes have been described, including collagen vascular diseases, arteritis, trauma, and arterial dysplasia [10].

Two decades ago, $>90 \%$ of all patients were symptomatic [3]; however, more recently, diagnosed SMAAs have been asymptomatic and discovered as incidental findings on abdominal imaging [2]. Stone et al [2] reported in their study that $48 \%$ of all patients were asymptomatic, and in the study by Jiang et al. [8], this was even higher, with $70 \%$ of patients being asymptomatic. These findings are consistent with the fact that more abdominal CT scans and other forms of cross-sectional imaging are being performed. Another possible explanation is the widespread use of antibiotics, which could potentially prevent an infectious cause of SMAAs. Although a decrease of $50 \%$ for infectious causes has been described in recent literature $[2,10]$, the SMA remains the visceral artery most affected by infections [14].

Patients can present with a wide range of symptoms, including abdominal pain, nausea, vomiting, a pulsatile mass, or gastrointestinal bleeding. Mycotic aneurysms are usually accompanied by a triad of fever, abdominal pain, and a pulsatile mass. A pulsatile mass is present in $50 \%$ of symptomatic patients. Acute presentation, including small bowel ischemia caused by thrombosis and excessive hemorrhage caused by rupture, is described in up to $38 \%$ of patients [10]. This is concerning, because the mortality rate after rupture is close to $35 \%$ [2]. In these patients, emergent laparotomy is recommended. The indications for repair include 


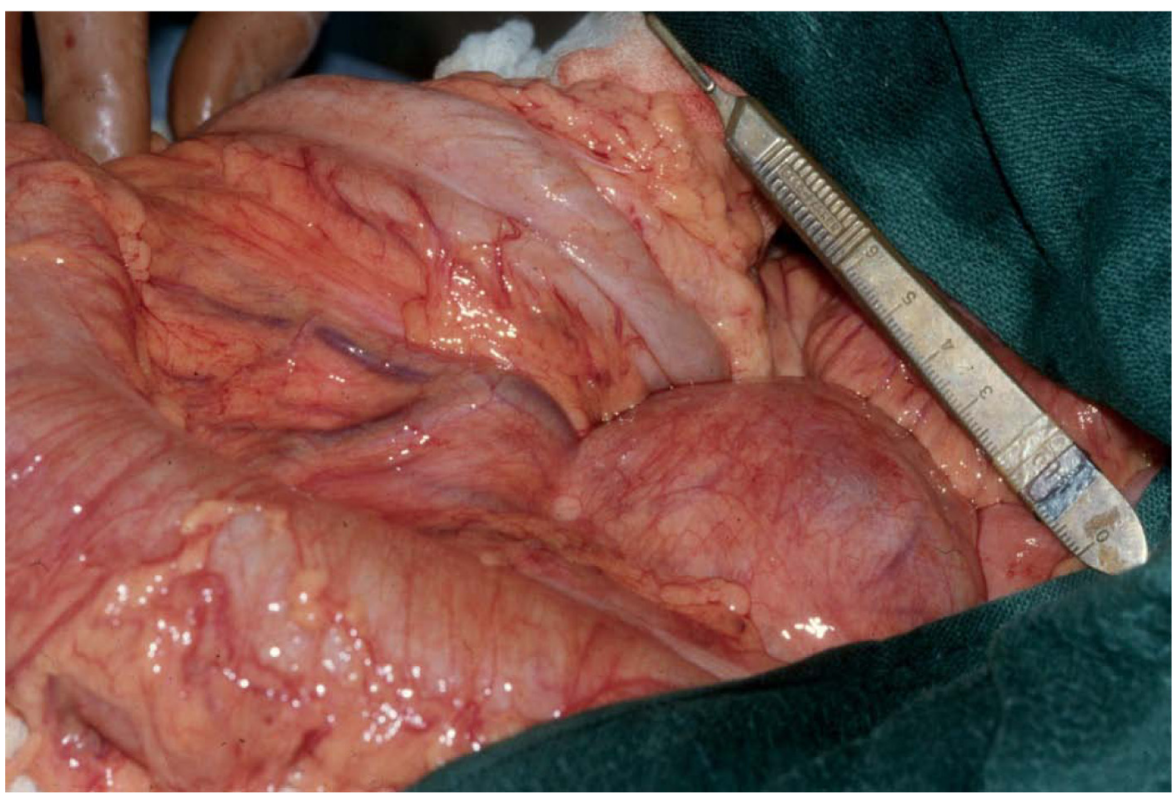

Figure 4. Intraoperative picture of the giant superior mesenteric artery aneurysm.

Table 1. Largest Studies of Superior Mesenteric Artery Aneurysms

\begin{tabular}{|c|c|c|c|c|c|c|c|c|c|c|}
\hline Article & $\begin{array}{l}\text { No. of } \\
\text { patients }\end{array}$ & $\begin{array}{l}\text { Age, } \\
y\end{array}$ & $\mathrm{M} / \mathrm{F}$ & $\begin{array}{l}\text { Aneurysm } \\
\text { data }\end{array}$ & Symptoms & $\begin{array}{l}\text { Emergent/ } \\
\text { elective }\end{array}$ & $\begin{array}{l}\text { OR/ EV/ } \\
\text { NM }\end{array}$ & $\begin{array}{l}\text { Technical } \\
\text { success, \% }\end{array}$ & $\begin{array}{l}30-d \\
\text { mortality \% }\end{array}$ & $\begin{array}{l}\text { Complications } \\
\text { (Follow-up, mo) }\end{array}$ \\
\hline $\begin{array}{l}\text { Carmeci et al. } \\
2000 \text { [7] }\end{array}$ & $5 *$ & 59 & $2 / 3$ & NA & $100 \% \mathrm{AbP} ; 80 \% \mathrm{R}$ & NA & $4 / 1 / 0$ & 100 & $0 \%$ & $0 \%(36)$ \\
\hline $\begin{array}{l}\text { Stone et al. } \\
2002[2]\end{array}$ & 21 & 59 & $14 / 7$ & $\begin{array}{l}62 \% \text { calcified; } \\
5 \% \\
\text { infectious }\end{array}$ & $\begin{array}{l}\text { 48\% AS; 24\% AbP; } \\
\text { 38\% R }\end{array}$ & $8 / 13$ & $12 / 3 / 6$ & NA & $\begin{array}{l}38 \% \text { in emergent } \\
\text { group; } 0 \% \text { in } \\
\text { elective group }\end{array}$ & $\begin{array}{l}0 \% \text { in emergent } \\
\text { group; } 25 \% \text { in } \\
\text { elective group } \\
\text { (56) }\end{array}$ \\
\hline $\begin{array}{l}\text { Marone et al. } \\
2011 \text { [9] }\end{array}$ & $6 *$ & 58 & $6 / 0$ & $\begin{array}{l}\text { Mean size: } \\
3.4 \mathrm{~cm}\end{array}$ & NA & NA & $3 / 3 / 0$ & 100 & $17 \%$ & $17 \%(\mathrm{NA})$ \\
\hline $\begin{array}{l}\text { Jiang et al. } \\
2011 \text { [8] }\end{array}$ & 10 & 57 & $4 / 6$ & $\begin{array}{l}\text { Mean size: } \\
3.5 \mathrm{~cm}\end{array}$ & $\begin{array}{l}70 \% \text { AS; } 10 \% \text { AbP; } \\
\quad 10 \% \text { R }\end{array}$ & $1 / 9$ & $2 / 5 / 2$ & 100 & $10 \%$ & $11 \%(30.9)$ \\
\hline
\end{tabular}

$\mathrm{M}$ indicates male; F, female; OR, open repair; EV, endovascular repair; NM, nonoperative management; AbP, abdominal pain; $A S$, asymptomatic; R, rupture; NA, not available.

*Part of a study of all visceral artery aneurysms.

SMAAs with a diameter $>2 \mathrm{~cm}$, symptomatic SMAAs, and rapidly growing SMAAs. Because the natural history of SMAAs is not well-defined, there is still some controversy about the absolute indications $[9,15]$.

Open repair is still considered the "gold standard" for all SMAAs in patients who require treatment. Open surgical repair can be performed by surgical resection with arterial reconstruction, as illustrated by our case report, or by ligation of the vessel without reconstruction. The primary goal of therapy is to exclude the aneurysmal sac from the blood circulation. Ligation without reconstruction should only be performed in cases in which sufficient collaterals are present to provide collateral flow [16].
The evolution of endovascular techniques has also impacted the management of visceral artery aneurysms. These minimally invasive procedures generally are associated with less operative morbidity and mortality, shorter hospitalization, fewer complications, and a better perioperative quality of life [17]. The recent literature shows that endovascular treatment could play an important role in the emergent treatment of ruptured SMAAs, and technical success rates up to $90 \%$ have been reported [18]; however, endovascular treatment such as stenting and coil embolization is not a feasible option in every VAA, and SMAA in particular. In the current literature, there are only a few case reports and small case series that report the use of endovascular treatment of 
SMAAs $[8,19,20]$. In planning of the endovascular procedure, the entire affected artery must be assessed carefully with angiography or CT angiography, to evaluate the proximal and distal landing zone and the presence of side branches. Covering of these side branches could potentially lead to mesenteric ischemia, with devastating consequences. However, even if careful angiographic evaluation is performed, it is not likely to show all side branches. Jiang et al. [8] reported that they found many more branches originating from the aneurysm during surgical treatment than were apparent on preoperative SMA angiography. Future studies are still needed to show the long-term results of stenting and coil embolization of SMAAs before it can be considered a safe and effective treatment.

SMAAs remain a rare entity with a wide range of clinical presentations. With the increased use of abdominal cross-sectional imaging, more asymptomatic SMAAs are being detected, and the relative portion of mycotic aneurysms during diagnosis is decreasing. High rupture and other complication rates are associated with SMAAs, so early treatment is recommended for symptomatic, rapidly growing, and relatively large SMAAs. Open repair, primarily ligation and excision of the aneurysm, remains the gold standard. Endovascular treatment has developed into a viable option, but more research is needed to evaluate and optimize this treatment. Because of the low incidence and the lack of large studies, there are no guidelines for postoperative management; however, it is recommended that follow-up be performed when symptoms occur, especially in the first years after intervention, when the risk of bypass occlusion is the highest, although the complication and reintervention rates are very low because of the good long-term results [15].

\section{Comment on this Article or Ask a Question}

\section{References}

1. Carr SC, Pearce WH, Vogelzang RL, McCarthy WJ, Nemcek AA Jr., Yao JS. Current management of visceral artery aneurysms. Surgery. 1996;120:627-633. 10.1016/S00396060(96)80009-2

2. Stone WM, Abbas M, Cherry KJ, Fowl RJ, Gloviczki P. Superior mesenteric artery aneurysms: Is presence an indication for intervention? J Vasc Surg. 2002;36:234-237. 10.1067/ mva.2002.125027

3. Dasari BV, Mullan M, Lau L, Loan W, Lee B. A $6.5-\mathrm{cm}$ pseudoaneurysm of the superior mesenteric artery managed by primary surgical repair.Vascular.2013;21:39-42.10.1258/ vasc.2010.cr0249

4. McNamara MF, Griska LB. Superior mesenteric artery branch aneurysms. Surgery. 1980;88:625-630.

5. Verma BS, Bose AK, Bhatia HC, Katoch R. Superior mesenteric artery branch aneurysm diagnosed by ultrasound. Br J Radiol. 1991; 64:169-171. 10.1259/0007-1285-64-758-169

6. DeBakey ME, Cooley DA. Successful resection of mycotic aneurysm of superior mesenteric artery: Case report and review of literature. Am Surg. 1953;19:202-212.

7. Carmeci C, McClenathan J. Visceral artery aneurysms as seen in a community hospital. Am J Surg. 2000;179:486-489. 10.1016/ S0002-9610(00)00380-9

8. Jiang J, Ding X, Su Q, et al. Therapeutic management of superior mesenteric artery aneurysms. J Vasc Surg. 2011;53:1619-1624. 10.1016/j.jvs.2011.02.004

9. Marone EM, Mascia D, Kahlberg A, Brioschi C, Tshomba Y, Chiesa R. Is open repair still the gold standard in visceral artery aneurysm management? Ann Vasc Surg. 2011;25:936946. 10.1016/j.avsg.2011.03.006

10. Messina LM, Shanley CJ. Visceral artery aneurysms. Surg Clin North Am. 1997;77:425442. 10.1016/S0039-6109(05)70559-4

11. Kopatsis A, D'Anna JA, Sithian N, Sabido F. Superior mesenteric artery aneurysm: 45 years later. Am Surg. 1998;64:263-266.

12. de Leeuw K, Goorhuis JF, Tielliu IF, et al. Superior mesenteric artery aneurysm in a 9-year-old boy with classical Ehlers-Danlos syndrome. Am J Med, Genet A. 2012;158A: 626-629.

13. Yuksel M, Islamoglu F, Egeli U, Posacioglu $H$, Yilmaz R, Buket S. Superior mesenteric artery aneurysm. Asian Cardiovasc Thorac Ann. 2002;10:61-63.

14. Ohmi M, Kikuchi Y, Ito A, Ouchi M. Superior mesenteric artery aneurysm secondary to infectious endocarditis. J Cardiovasc Surg (Torino). 1990;31:115-117.

15. Pulli R, Dorigo W, Troisi N, Pratesi G, Innocenti AA, Pratesi C. Surgical treatment of visceral artery aneurysms: A 25-year experience. J Vasc Surg. 2008;48:334-342. 10.1016/ j.jvs.2008.03.043

16. Komori K, Mori E, Yamaoka T, et al. Successful resection of superior mesenteric artery aneurysm: A case report and review of the literature. J Cardiovasc Surg (Torino). 2000; 41:475-478.

17. Prinssen $M$, Verhoeven EL, Buth J, et al. A randomized trial comparing conventional and endovascular repair of abdominal aortic aneurysms. N Engl J Med. 2004;351:16071618. 10.1056/NEJMoa042002

18. Sachdev U, Baril DT, Ellozy SH, et al. Management of aneurysms involving branches of the celiac and superior mesenteric arteries: A comparison of surgical and endovascular therapy. J Vasc Surg. 2006;44:718-724. 10.1016/j.jvs.2006.06.027

19. Mendonca CT, Weingartner J, de Carvalho CA, Costa DS. Endovascular treatment of contained rupture of a superior mesenteric artery aneurysm resulting from neurofibromatosis type I. J Vasc Surg. 2010;51:461-464. 10.1016/j.jvs.2009.08.039

20. Drescher $R$, Koster $O$, von Rothenburg $T$. Superior mesenteric artery aneurysm stent graft. Abdom Imaging. 2006;31:113-116. 10. 1007/s00261-005-0355-z

Cite this article as: Hogendoorn W Schlösser FJV, Sumpio BE. A Giant Superior Mesenteric Artery Aneurysm Mimicking an Abdominal Aortic Aneurysm. Aorta 2013;1(1):52-56. DOI: http://dx.doi. org/10.12945/j.aorta.2013.12.010 